\title{
Energy Efficient Sustainable Communication System Design for Space Craft Operating in the Coldest Places of Solar System
}

\author{
Shivani Sharma \\ Gyancity Research Lab, Gurgaon, India \\ shalu16sharma@gmail.com
}

\begin{abstract}
In this big Universe communication is need of the hour. To make efficient communication system, it must consume less amount of power. So the goal is to maintain less power by changing output load at different frequencies. With change in output load ambient temperature also varies and becomes very low up to absolute zero temperature. This leads to the innovation of making a communication system that can work in the coldest places of the space.
\end{abstract}

Keywords-Communication System, Temperature, Power, Efficient.

\section{INTRODUCTION}

THIS work is mainly related to design of energy efficient and sustainable communication system for space craft operating in the coldest region of the solar system. For that, we have studied the coldest place on the earth, in the solar system and also in the universe. While all the entity in this universe shown in Table 1 is much chillier than any place on Earth, one of the coldest spots in space is space itself. The cosmic microwave background radiation that permeates the universe (and is the remnant energy of the theoretical Big Bang) has a temperature of 2.725 degrees Kelvin-that's minus 455 degrees Fahrenheit, or minus 270 degrees Celsius.[6]

Table 1: Temperature of Different Entity in Universe

\begin{tabular}{|l|l|}
\hline Heavenly Body & Lowest Temperature (Recorded) \\
\hline Europa & -300 Fahrenheit or $-184^{\circ} \mathrm{C}$ \\
\hline Uranus & -371 Fahrenheit or $-224^{\circ} \mathrm{C}$ \\
\hline Pluto & -292 Fahrenheit or $-180^{\circ} \mathrm{C}$ \\
\hline Cosmic Microwave (Space Itself) & -455 Fahrenheit or $-270^{\circ} \mathrm{C}$ \\
\hline Plank Spacecraft (Man Made) & -459.49 Fahrenheit or $-273.05^{\circ} \mathrm{C}$ \\
\hline
\end{tabular}

The chilliest known spot in space isn't an icy comet, or even space itself, but is something man-made: the European Space Agency's Planck spacecraft. On its way to its final orbiting point - where it will observe the remnant radiation of the theoretical Big Bang - the telescope cooled down to its operating temperature of minus 459.49 degrees Fahrenheit (minus 273.05 Celsius). This temperature is just 0.1 Celsius above absolute zero, the 
coldest temperature theoretically possible in our universe. We are also generating the demand of extreme environment temperature (nearer to absolute zero) by controlling junction temperature to $25^{\circ} \mathrm{C}$.

Table 2: On $10 \mathrm{GHz}$ Operating Frequency and $25^{\circ} \mathrm{C}$ Junction Temperature

\begin{tabular}{|l|l|l|}
\hline Capacitance & $\begin{array}{l}\text { Required Environment } \\
\text { Temperature (RET) }\end{array}$ & $\begin{array}{l}\text { Entity in Universe, whose } \\
\text { temperature is nearer to RET [1] }\end{array}$ \\
\hline $10 \mathrm{pF}$ & $-63^{\circ} \mathrm{C}$ & Mars (-82 to 0) \\
\hline $20 \mathrm{pF}$ & $-89.6^{\circ} \mathrm{C}$ & Earth (-89 to 58) \\
\hline $30 \mathrm{pF}$ & $-115.9^{\circ} \mathrm{C}$ & Ceres (-106) \\
\hline $40 \mathrm{pF}$ & $-142.2^{\circ} \mathrm{C}$ & Jupiter (-150) \\
\hline
\end{tabular}

\section{RELATED WORK}

Our work concentrates on making a communication system in the coolest places of the Universe. We have worked on power consumptions at different ambient temperatures which are even very low. Some of related work is:

\subsection{Energy Efficient Sensor Circuit Design For Space Applications [2]}

The above mentioned paper has worked on making a wireless sensor that can be used in space satellites as well as robots for space. A high level of sensing quality has been maintained by the sensor. They have also precisely focused on power consumption i.e. dynamic power consumption of the system as well. This research is made to make sensor circuit where as we have focused on making a communication system design for the coldest places of the universe. The communication system we have designed is power efficient and we have also mentioned the reduction in total power in the results.

\subsection{Energy Efficient Platform Designed for SDMA Applications in Mobile Wireless Sensor Networks [3]}

This paper is related to designing of platform for SDMA applications in mobile wireless networks. They had used a new open source platform described as Data Truck. They have used long term sleep mode which got a support from various power supplying techniques for clock and main board as well. The smart antenna was further integrated in order to integrate the data. Our research also emphasizes on developing an energy efficient communication system but for coldest places of the solar system. So the approach is to consume less power as much as possible but for different systems.

\subsection{Wireless Communication Design for Remote Monitoring [4]}

This paper relates to design a wireless communication design for remote monitoring which uses OFDM technology. They developed a system for monitoring in special environmental condition and our paper focuses on designing a communication system for coldest places of universe which will also be energy efficient. So both papers have developed communication systems but environmental conditions are different. We have approach to design the system energy efficient too.

\subsection{A network-on-chip Approach for Reconfigurable System-on-Chip Design in Space Applications [5]}


This paper has done work on designing a system for space applications like Venus Express mission [5]. They have developed a flexible Network-on-Chip approach. But there is no condition like coldest places. We have achieved the ambient temperature up to absolute zero. Above mentioned research has no relation with saving energy. We have achieved the low power which leads to high performance of communication system i.e. to make the system efficient.

\section{Problem Statement or Research Gap}

There are thousands of research work done for the designing the communication system for earth. But when it is about the universe there comes a gap. This research mainly concentrated on designing a communication system reliable for coldest places of universe and energy efficient [8-16] as well. Our idea is to meet the research gap that has been created between designing the systems for universe instead of our planet earth only.

\section{RESEARCH METHODOLOGY}

The adapted technique in this paper is Xilinx software. Using Xilinx the different readings of total power consumed are analyzed carefully. When output load is varied, different values of ambient temperature are noted down. During this research the value of temperature noted down lies in very low temperature range which even recedes from the lowest possible temperature. Since such low temperature is obtained the idea is to design the energy efficient [8-16] communication system for various parts of universe having very low temperature. Such places have been mentioned in introduction having temperatures close to the values obtained by using Xilinx.

\section{DATA ANALYSIS AND INTERPRETATION}

\section{A. Results on $1 \mathrm{GHz}$ Operating Frequency}

Table 3: Total Power and Temperature with Output Load from $10-50$ at $1 \mathrm{GHz}$

\begin{tabular}{|l|l|l|l|l|l|}
\hline Output Load & 10 & 20 & 30 & 40 & 50 \\
\hline $\begin{array}{l}\text { Ambient } \\
\text { Temperature }\end{array}$ & $15^{\circ} \mathrm{C}$ & $12.4^{\circ} \mathrm{C}$ & $9.8^{\circ} \mathrm{C}$ & $7.1^{\circ} \mathrm{C}$ & $4.5^{\circ} \mathrm{C}$ \\
\hline Total Power & 4.471 & 5.662 & 6.853 & 8.043 & 9.234 \\
\hline
\end{tabular}

There is $17.33 \%, 36.66 \%, 56.66 \%$ and $70 \%$ reduction in the ambient temperature when the output load is scaled from $10 \mathrm{pF}$ to $20 \mathrm{pF}, 30 \mathrm{pF}, 40 \mathrm{pF}$ and $50 \mathrm{pF}$ respectively and also there 
is $12.89 \%, 25.7 \%, 38.6 \%$ and $51.5 \%$ reduction in the total power when we scale down output load from $50 \mathrm{pF}$ to $40 \mathrm{pF}, 30 \mathrm{pF}, 20 \mathrm{pF}$ and $10 \mathrm{pF}$ respectively.

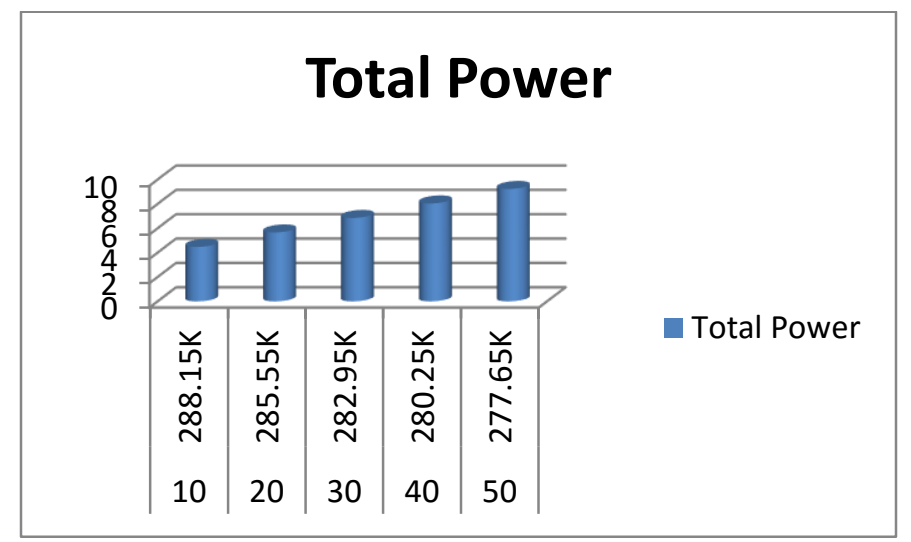

Figure1: Output Load from 10-50 with Temperature and Total Power at $1 \mathrm{GHz}$

Table4: Total Power and Temperature with Output Load from 60-100 at $1 \mathrm{GHz}$

\begin{tabular}{|l|l|l|l|l|l|}
\hline Output Load & 60 & 70 & 80 & 90 & 100 \\
\hline $\begin{array}{l}\text { Ambient } \\
\text { Temperature }\end{array}$ & $1.9^{\circ} \mathrm{C}$ & $-0.7^{\circ} \mathrm{C}$ & $-3.4^{\circ} \mathrm{C}$ & $-6.0^{\circ} \mathrm{C}$ & $-8.6^{\circ} \mathrm{C}$ \\
\hline Total Power & 10.425 & 11.616 & 12.807 & 13.998 & 15.188 \\
\hline
\end{tabular}

There is $136.8 \%, 278 \%, 415.7 \%$ and $552.6 \%$ reduction in the ambient temperature when output load is scaled from $60 \mathrm{pF}$ to $70 \mathrm{pF}, 80 \mathrm{pF}, 90 \mathrm{pF}$ and $100 \mathrm{pF}$ respectively and also there is $07.8 \%, 14.99 \%, 23.5 \%$ and $31.3 \%$ reduction in total power when we scale down output load from $100 \mathrm{pF}$ to $90 \mathrm{pF}, 80 \mathrm{pF}, 70 \mathrm{pF}$ and $60 \mathrm{pF}$ respectively.

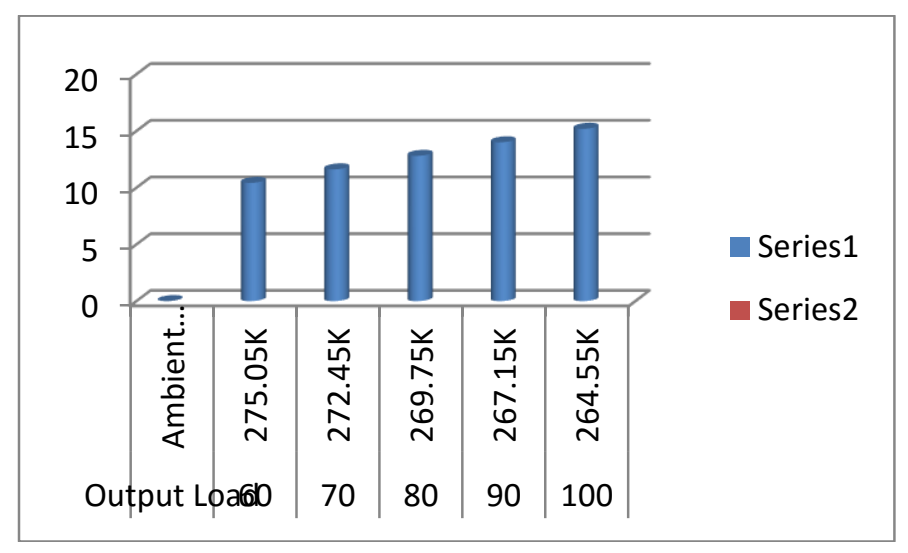

Figure 2:Output Load from 60-100 with Temperature and Total Power at $1 \mathrm{GHz}$

\section{B. Results on $10 \mathrm{GHz}$ Operating frequency}

Table 4: Variation of total power and temperature with output load at $10 \mathrm{GHz}$

\begin{tabular}{|l|l|l|l|l|l|}
\hline Output Load & 10 & 20 & 30 & 40 & 50 \\
\hline Ambient & - & - & - & - & - \\
Temperature & $63.4^{\circ} \mathrm{C}$ & $89.6^{\circ} \mathrm{C}$ & $115.9^{\circ} \mathrm{C}$ & $142 .^{\circ} \mathrm{C}$ & $168.5^{\circ} \mathrm{C}$ \\
\hline
\end{tabular}




\begin{tabular}{|l|l|l|l|l|l|}
\hline Total Power & 39.97 & 51.88 & 63.79 & 75.70 & 87.60 \\
\hline
\end{tabular}

There is $-41 \%,-82.8 \%,-123.9 \%$ and $-165.7 \%$ reduction in the ambient temperature when the output load is scaled from $10 \mathrm{pF}$ to $20 \mathrm{pF}, 30 \mathrm{pF}, 40 \mathrm{pF}$ and $50 \mathrm{pF}$ respectively and also there is $13.5 \%, 27.1 \%, 40.77 \%$ and $54 \%$ reduction in the total power when we scale down output load from $50 \mathrm{pF}$ to $40 \mathrm{pF}, 30 \mathrm{pF}, 20 \mathrm{pF}$ and $10 \mathrm{pF}$ respectively.

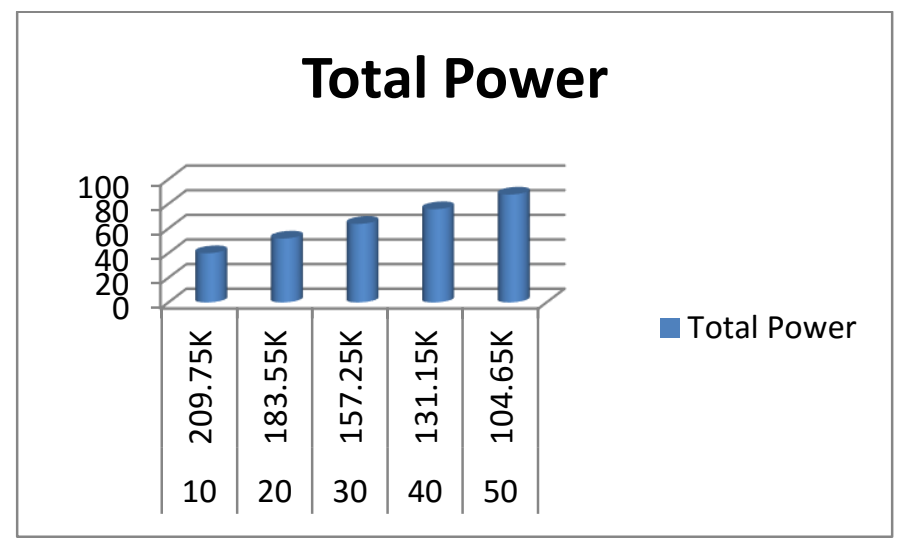

Figure3: Variation of total power and temperature with output load at $10 \mathrm{GHz}$

Table 5: Variation of total power and temperature with output load at $1 \mathrm{GHz}$

\begin{tabular}{|l|l|l|l|l|l|}
\hline Output Load & 60 & 70 & 80 & 90 & 100 \\
\hline Ambient & - & - & - & - & - \\
Temperature & $194.8^{\circ} \mathrm{C}$ & $221.1^{\circ} \mathrm{C}$ & $247.4^{\circ} \mathrm{C}$ & $273.7^{\circ} \mathrm{C}$ & $300^{\circ} \mathrm{C}$ \\
\hline Total Power & 99.51 & 111.4 & 123.3 & 187.4 & 147.15 \\
\hline
\end{tabular}

There is $-13.50 \%,-27 \%,-40.50 \%$ and $-54 \%$ reduction in the ambient temperature when the output load is scaled from $60 \mathrm{pF}$ to $70 \mathrm{pF}, 80 \mathrm{pF}, 90 \mathrm{pF}$ and $100 \mathrm{pF}$ respectively and also there is $-27.33 \%, 16.20 \%, 24.29 \%$ and $32.37 \%$ reduction in total power when we scale down output load from $100 \mathrm{pF}$ to $90 \mathrm{pF}, 80 \mathrm{pF}, 70 \mathrm{pF}$ and $60 \mathrm{pF}$ respectively. Observing carefully the values of ambient temperatures the value at output load 90 and 100 reduced from absolute zero temperature.

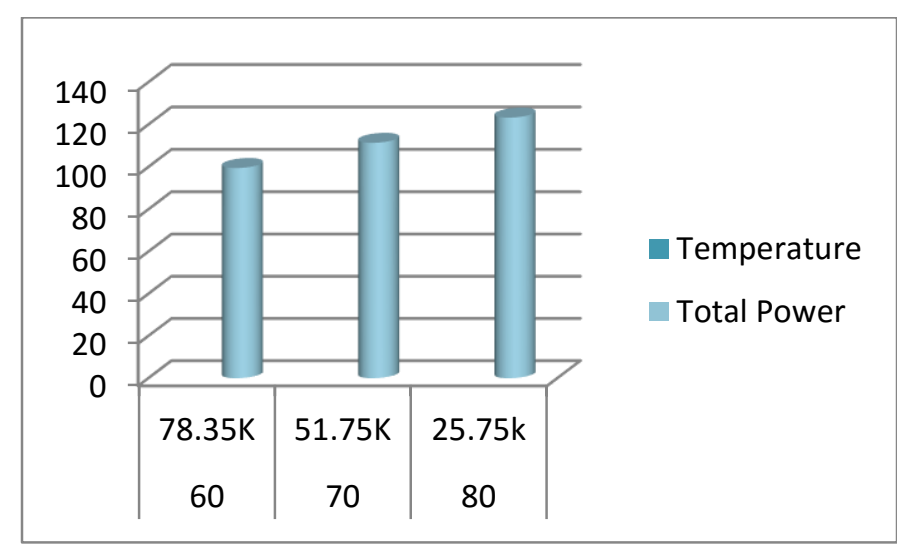

Figure 4: Variation of total power and temperature with output load at $10 \mathrm{GHz}$ 
C. Results on $0.1 \mathrm{GHz}$

Table 6: Variation of total power and temperature with output load at $0.1 \mathrm{GHz}$

\begin{tabular}{|l|l|l|l|l|l|}
\hline Output Load & 10 & 20 & 30 & 40 & 50 \\
\hline Ambient Temperature & $22.9^{\circ} \mathrm{C}$ & $22.6^{\circ} \mathrm{C}$ & $22.3^{\circ} \mathrm{C}$ & $22.1^{\circ} \mathrm{C}$ & $21.8^{\circ} \mathrm{C}$ \\
\hline Total Power & 0.926 & 1.045 & 1.164 & 1.283 & 1.402 \\
\hline
\end{tabular}

There is $1.31 \%, 2.62 \%, 7.8 \%$ and $4.8 \%$ reduction in the ambient temperature when the output load is scaled from $10 \mathrm{pF}$ to $20 \mathrm{pF}, 30 \mathrm{pF}, 40 \mathrm{pF}$ and $50 \mathrm{pF}$ respectively and also there is $8.4 \%, 16.97 \%, 25.46 \%$ and $33.95 \%$ reduction in the total power when we scale down output load from $50 \mathrm{pF}$ to $40 \mathrm{pF}, 30 \mathrm{pF}, 20 \mathrm{pF}$ and $10 \mathrm{pF}$ respectively.

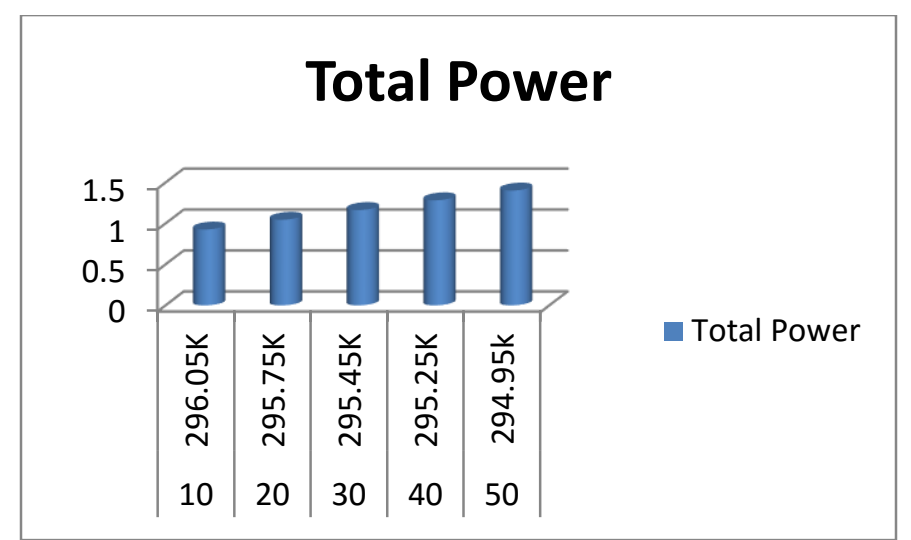

Figure 5: Variation of total power and temperature with output load at $0.1 \mathrm{GHz}$

Table 7: Variation of total power and temperature with output load at $0.1 \mathrm{GHz}$

\begin{tabular}{|l|l|l|l|l|l|}
\hline Output Load & 60 & 70 & 80 & 90 & 100 \\
\hline $\begin{array}{l}\text { Ambient } \\
\text { Temperature }\end{array}$ & $21.5^{\circ} \mathrm{C}$ & $21.3^{\circ} \mathrm{C}$ & $21.0^{\circ} \mathrm{C}$ & $20.8^{\circ} \mathrm{C}$ & $20.5^{\circ} \mathrm{C}$ \\
\hline Total Power & 1.522 & 1.641 & 1.760 & 1.879 & 1.998 \\
\hline
\end{tabular}

There is $0.93 \%, 2.32 \%, 3.25 \%$ and $40 \%$ reduction in the ambient temperature when the output load is scaled from $60 \mathrm{pF}$ to $70 \mathrm{pF}, 80 \mathrm{pF}, 90 \mathrm{pF}$ and $100 \mathrm{pF}$ respectively and also there is $5.95 \%, 11.91 \%, 17.86 \%$ and $23.82 \%$ reduction in total power when we scale down output load from $100 \mathrm{pF}$ to $90 \mathrm{pF}, 80 \mathrm{pF}, 70 \mathrm{pF}$ and $60 \mathrm{pF}$ respectively. 


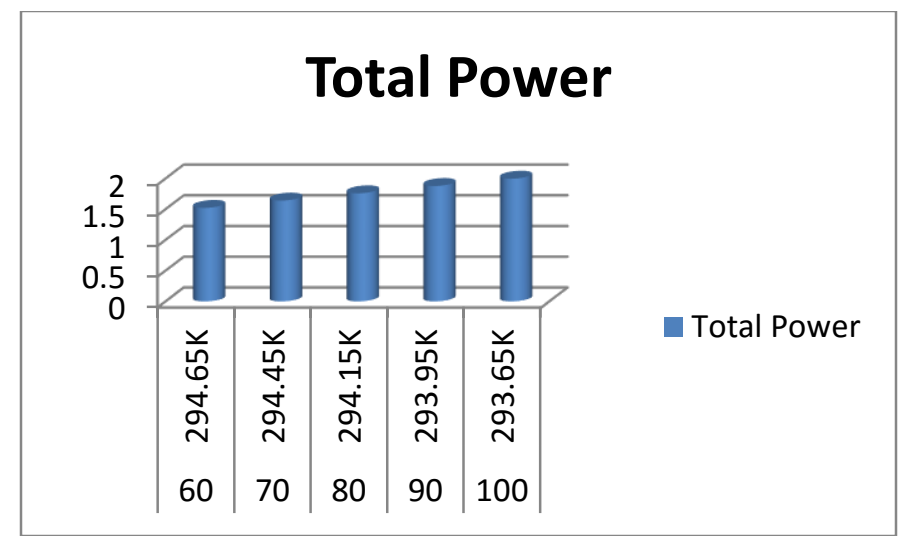

Figure 6: Variation of total power and temperature with output load at $0.1 \mathrm{GHz}$

\section{CONCLUSION}

The work has been done precisely or accurately to design the communication system for space craft which will work in the coldest temperatures of the universe. Through Xilinx software we have varied the value of output load at different frequencies and came with different values of power consumed and different ambient temperatures too. From the analyses we came to idea of designing a communication system that can be efficient in the coldest places.

\section{FUTURE SCOPE}

Energy Saving is very important aspect as the World is facing energy efficiency problems day by day. That's why it becomes important to make system designs profitably efficient. The total power consumption of a realistic and appropriate technology for future highperformance of system would probably be less. [7]In future we are not limiting for making communication system for earth only. Area of work is increasing and making communication system for space or universe will really help us to increase our workspace. In future different software for simulation may be used that can provide us with better results. Vertex-6 FPGA family has been used by in this research. Further Vertex-7 can be used. Various communication systems can be made in future as per requirements.

\section{REFERENCES}

[1]. Temperature chart available at: http://www.windows2universe.org/our_solar_system/planets_table.html

[2]. J. Kang, M. Sung, and T. T. Jeong. "Energy-efficient Sensor Circuit Design for Space Applications." Aerospace Conference, IEEE 2007.

[3]. X.Zhang,G. Chen. "Energy-efficient platform designed for SDMA applications in mobile wireless sensor networks." Wireless Communications and Networking Conference, IEEE, 2011.

[4]. A.Mainwaring "Wireless sensor networks for habitat monitoring."Proceedings of the 1st ACM international workshop on Wireless sensor networks and applications. ACM, 2002.

[5]. B.Osterloh. "Socwire: A network-on-chip approach for reconfigurable system-on-chip designs in space applications." Adaptive Hardware and Systems, 2008. AHS'08. NASA/ESA Conference on. IEEE, 2008.

[6]. Energy

Information

available

at: http://www.amnh.org/education/resources/rfl/web/essaybooks/cosmic/cs_radiation.html

[7]. S. Aleksić "Analysis of power consumption in future high-capacity network nodes." Journal of Optical Communications and Networking 1.3 2009: Pp.245-258.

[8]. Shivani Madhok, Bishwajeet Pandey, Amanpreet Kaur, D M Akbar Hussain, Mohamed Hashim Minver, "HSTL IO Standard Based Energy Efficient Multiplier Design using Nikhilam 
Navatashcaramam Dashatah on 28nm FPGA", International Journal of Control and Automation, Vol.8, No.8, August 2015. http://www.sersc.org/journals/IJCA/vol8_no8/5.pdf

[9]. Sumita Nagah, Bishwajeet Pandey, Kartik Kalia, Ravinder Kaur, Md. Saifur Rahman Mahbub-ENoor, "I/O Standards Based on Green Communication Using Fibonacci Generator Design on FPGA", International Journal of Control and Automation, Vol.8, No.8, August 2015. http://www.sersc.org/journals/IJCA/vol8_no8/13.pdf

[10]. Bishwajeet Pandey, Vandana Thind, Simran Kaur Sandhu, Tamanna Walia, Sumit Sharma, "SSTL Based Power Efficient Implementation of DES Security Algorithm on 28nm FPGA", International Journal of Security and Its Application, Vol.9, No.7, July 2015, pp.267-274, http://www.sersc.org/journals/IJSIA/vol9_no7_2015/23.pdf

[11]. Anirudh Khanna, Bishwajeet Pandey, Bhale Pradeepkumar, Kartik Kalia, Kushagra Vashishta and Teerath Das, "A Study of Today's A.I. through Chatbots and a Rediscovery of Machine Intelligence", International Journal of u- and e- Service, Science and Technology, Vol.8, No. 7, July 2015, pp.277-284. http://www.sersc.org/journals/IJUNESST/vol8_no7/28.pdf

[12]. Tanesh Kumar, Bishwajeet Pandey, Sayed Hyder Abbas Musavi, Noor Zaman, "CTHS Based Energy Efficient Thermal Aware Image ALU Design on FPGA", Springer Wireless Personal Communications, An International Journal, ISSN:0929-6212(print), ISSN:1572-834X(electronic), SCI Indexed, Vol.83, No.1, July 2015. http://link.springer.com/article/10.1007/s11277-015-2801-8

[13]. Deepa Singh, Kanika Garg, Ravneet Singh, Bishwajeet Pandey, Kartik Kalia, Hasmatullah Noori, "Thermal aware Internet of Things Enable Energy Efficient Encoder Design for security on FPGA", International Journal of Security and Its Applications, Vol.9, No.6, pp. 271-278, June 2015. http://www.sersc.org/journals/IJSIA/vol9_no6_2015/26.pdf

[14]. Sayed Hyder Abbas Musavi, B. S. Chowdhry, Tanesh Kumar, Bishwajeet Pandey, Wanod Kumar, "IoTs Enable Active Contour Modeling Based Energy Efficient and Thermal Aware Object Tracking on FPGA", Springer Wireless Personal Communications, ISSN:1572-834X(electronic), SCI Indexed, Vol.85, No.2, pp.529-543, 20 May 2015, http://link.springer.com/article/10.1007/s11277-015-2753-z

[15]. Tanesh Kumar, Bishwajeet Pandey, Teerath Das, and Bhavani Shankar Chowdhry, "Mobile DDR IO Standard Based High Performance Energy Efficient Portable ALU Design on FPGA", Springer Wireless Personal Communications, An International Journal, Volume 76, Issue 3 (2014), Page 569578, (SCI Indexed), http://link.springer.com/article/10.1007/s11277-014-1725-z/fulltext.html

[16]. S. M. Mohaiminul Islam, Bishwajeet Pandey, Shashank Jaiswal, Md. Mahbub-E-Noor and Shah Md. Tanvir Siddiquee, "Simulation of Voltage Scaling Aware Mobile Battery Charge Controller Sensor on FPGA", "Advanced Materials Research", ISSN:1022-6680, Vol. 893 (2014) pp 798-802, 2014, Trans Tech Publications, Switzerland, (SCOPUS Indexed), http://www.scientific.net/AMR.893.798 